\title{
Article \\ Study on the Properties of Coated Cutters on Functionally Graded WC-Co/Ni-Zr Substrates with FCC Phase Enriched Surfaces
}

\author{
Shidi Li ${ }^{1}$, Xiangyuan Xue ${ }^{1}$, Jiaxing Chen ${ }^{1}$, Tengxuan Lu ${ }^{1}$, Zhe Zhao ${ }^{1}$, Xin Deng ${ }^{1, *}$, Zhongliang Lu ${ }^{2,3}$, \\ Zhongping Wang ${ }^{4}$, Zhangxu $\mathrm{Li}^{4}$ and Zhi Qu ${ }^{5}$
}

check for

updates

Citation: Li, S.; Xue, X.; Chen, J.; Lu, T.; Zhao, Z.; Deng, X.; Lu, Z.; Wang,

Z.; Li, Z.; Qu, Z. Study on the

Properties of Coated Cutters on

Functionally Graded WC-Co/Ni-Zr Substrates with FCC Phase Enriched Surfaces. Crystals 2021, 11, 1538.

https://doi.org/10.3390/cryst11121538

Academic Editors: Hao Yi,

Huajun Cao, Menglin Liu and Le Jia

Received: 20 November 2021

Accepted: 6 December 2021

Published: 9 December 2021

Publisher's Note: MDPI stays neutral with regard to jurisdictional claims in published maps and institutional affiliations.

Copyright: (c) 2021 by the authors. Licensee MDPI, Basel, Switzerland. This article is an open access article distributed under the terms and conditions of the Creative Commons Attribution (CC BY) license (https:// creativecommons.org/licenses/by/ $4.0 /)$.
1 School of Electromechanical Engineering, Guangdong University of Technology, Guangzhou 510006, China; 2112001395@mail2.gdut.edu.cn (S.L.); xuexiangyuan123@163.com (X.X.); c626443994@163.com (J.C.); 18320636910@163.com (T.L.); just4ujust4all@126.com (Z.Z.)

2 State Key Laboratory for Manufacturing Systems Engineering, Xi'an Jiaotong University, Xi'an 710049, China; zllu@xjtu.edu.cn

3 Guangdong Xi'an Jiaotong University Academy, Foshan 528300, China

4 Heyuan Fuma Cemented Carbide Co., Ltd., Heyuan 517583, China; wzp@fuma-carbide.com (Z.W.); 13825375320@139.com (Z.L.)

5 Guangdong Jin Ci San Wei Tech-Ltd., Foshan 528225, China; qz@fhzl3dp.com

* Correspondence: dengxin@gdut.edu.cn; Tel.: +86-020-39322925

\begin{abstract}
Currently, the research on mechanical behavior and cutting performance of functionally graded carbides is quite limited, which limits the rapid development of high-performance cemented carbide cutting tools. Based on WC-Co-Zr and WC-Ni-Zr, this study synthesized two kinds of cemented carbide cutters, i.e., the cemented carbide cutters with homogeneous microstructure and functionally graded carbide (FGC) cutters with FCC phase $\mathrm{ZrN}$-enriched surfaces. Furthermore, TiAlN coating has been investigated on these carbide cutters. Mechanical behavior, friction, wear performance, and cutting behavior have been investigated for these coated carbides and their corresponding substrates. It was found that, as compared with coated cutters on $\mathrm{WC}-\mathrm{Co} / \mathrm{Ni}-\mathrm{Zr}$ carbide substrates with homogeneous microstructures, the coated cutters on WC-Co/Ni-Zr FGC substrates with FCC phase-enriched surfaces show higher wear resistance and cutting life, and the wear mechanism during cutting is mainly adhesion wear.
\end{abstract}

Keywords: additive manufacture; cemented carbide; functionally graded structure; adhesive wear

\section{Introduction}

Cemented carbides, as ceramic matrix composites consisting of carbide matrix (mainly $\mathrm{WC}, \mathrm{TiC}$, and $\mathrm{TaC}$, etc.) and metal binders, have been widely used as cutting tools, molds, and mining and petroleum drilling tools due to their high hardness, strength, wear resistance, excellent oxidation resistance, and thermal stability [1-7]. With the rapid development of the modern manufacturing industry, more crucial requirements, such as simultaneously high wear resistance and high toughness, are being put forward on the performance of cemented carbides [8,9]. In order to obtain better properties, current development on cemented carbides is mainly focused on functionally graded carbides (FGCs) and cemented carbide coatings [10-14]. The FGCs shows gradient microstructures from surface to internal portion, which provides both higher wear resistance (surface) and toughness (internal portion) and hence better overall performance than conventional carbide with homogeneous microstructure [15-19]. The FGCs mainly include dual-phase FGC [20,21], the FGCs with binder phase-enriched surfaces [22,23], and the FGCs with face center cubic (FCC) phase-enriched surfaces [24]. The main preparation method of the FGC with an FCC phase-enriched surface is the nitriding method [25], which converts $\mathrm{N}$ in the sintering atmosphere and the elements (such as $\mathrm{Ti}, \mathrm{Zr}$, etc.) in carbides into nitride or 
carbon-nitride compounds of face-centered cubic crystals by thermal-chemical coupling, and then obtains the functionally graded carbide with FCC phase-enriched surface [26].

At present, there are quite limited study on the cutting performance of the FGCs with FCC phase-enriched surface, especially on the cutting performance of coated cutters on FGC substrates with FCC phase-enriched surface. This paper focuses on the microstructure, mechanical properties, and cutting properties of coated cutters on FGC substrates with FCC phase-enriched surface. The high-performance carbide cutters investigated in this study has potential applications in future additive/subtractive hybrid manufacturing.

\section{Materials and Methods}

The composition, gradient structure, and coating types of WC-Co/Ni- $\mathrm{Zr}$ cemented carbide are shown in Table 1 . The feedstock powders of $\mathrm{WC}, \mathrm{Co}, \mathrm{Ni}, \mathrm{Zr}$, and others with an average particle size of $1 \mu \mathrm{m}$ were weighed according to the composition in Table 1 and then put into a planetary ball mill with $2 \mathrm{wt} . \%$ paraffin wax and an appropriate amount of $\mathrm{n}$-heptane and mixed for $24 \mathrm{~h}$. The wet powder mixture slurry was dried in a rotary evaporator, and then pressed at $300 \mathrm{MPa}$ into $18 \mathrm{~mm} \times 18 \mathrm{~mm} \times 6 \mathrm{~mm}$ cutter billets. Afterwards, the cutter billets were dewaxed in a tube furnace at $400-550{ }^{\circ} \mathrm{C}$ in an argon atmosphere. The dewaxed cutter billets were sinter-hipped in a two-step process. Firstly, the dewaxed parts were sintered at $1450{ }^{\circ} \mathrm{C}$ for $30 \mathrm{~min}$ in an argon atmosphere at the pressure of $6 \mathrm{MPa}$. After furnace cooling, the pre-sintered parts were machined into a cutter shape of $12.5 \mathrm{~mm} \times 12.5 \mathrm{~mm} \times 5 \mathrm{~mm}$ and then polished. Secondly, all the machined parts were further sintered at $1450{ }^{\circ} \mathrm{C}$ in a nitrogen atmosphere at a pressure of $6 \mathrm{MPa}$ for $60 \mathrm{~min}$ to prepare the functionally graded cemented carbides (FGCs) with FCC phase-enriched surface. The dewaxing and sintering processes are shown in Figure 1. Two-step sintering is critical to the mechanical and frictional properties of FGCs. The first step of sintering with high pressure Argon results in the full density of carbides and the second step of sintering with high pressure nitrogen leads to the formation of gradient microstructure of FGCs. Upon two-step sintering, the FGCs achieve the high wear resistance of surface and the high toughness of the inner portion.

Table 1. The composition, microstructure, and coating type of WC-Co/Ni-Zr cemented carbides.

\begin{tabular}{ccccc}
\hline $\begin{array}{c}\text { Carbides } \\
\text { No. }\end{array}$ & Composition (wt.\%) & Sintering Process & Microstructure & Coating \\
\hline FC5-1 & WC-10Co-5Zr-0.5VC-2W & One-step/Ar & Homogeneous & Nothing \\
FC5-2 & WC-10Co-5Zr-0.5VC-2W & Two step / $\left(\mathrm{Ar}+\mathrm{N}_{2}\right)$ & Gradient & Nothing \\
FC5-3 & WC-10Co-5Zr-0.5VC-2W & One-step/Ar & Homogeneous & TiAlN \\
FC5-4 & WC-10Co-5Zr-0.5VC-2W & Two step / $\left./ \mathrm{Ar}+\mathrm{N}_{2}\right)$ & Gradient & TiAlN \\
FN1-1 & WC-10Ni-5Zr-0.5VC & One-step/Ar & Homogeneous & Nothing \\
FN1-2 & WC-10Ni-5Zr-0.5VC & Two step /(Ar+N 2$)$ & Gradient & Nothing \\
FN1-3 & WC-10Ni-5Zr-0.5VC & One-step/Ar & Homogeneous & TiAlN \\
FN1-4 & WC-10Ni-5Zr-0.5VC & Two step $/\left(\mathrm{Ar}+\mathrm{N}_{2}\right)$ & Gradient & TiAlN \\
\hline
\end{tabular}

In order to analyze the difference in properties between FGCs and conventional cemented carbides with homogeneous microstructure, the same WC-Co-Zr and WC-Ni-Zr parts were sintered in one-step sinter-hip process at $1450{ }^{\circ} \mathrm{C}$ for 90 min with $6 \mathrm{MPa}$ argon atmosphere to prepare the conventional cemented carbide with homogeneous microstructure. Finally, TiAlN coating was deposited on the above the FGCs and the conventional carbides with homogeneous microstructure by PVD method.

Zeiss Merlin high-resolution field emission electron microscope and energy spectrometer (Zeiss, Oberkochen, Germany) were used for microstructure and composition analysis. Nanoindentation was used to measure the coating hardness with a load of $10 \mathrm{mN}$. The bonding strength between coating and carbide substrate was measured by the RST3 Large Load Scratcher $[27,28]$. The UMT-TriboLab friction and wear tester (Bruker, Billerica, MA, USA) was used to test the wear resistance, friction, and wear performance of carbides. 
The GCr15 ball was used for the friction test of uncoated carbides with a load of $50 \mathrm{~N}$, the $\mathrm{Si}_{3} \mathrm{~N}_{4}$ ceramic ball was used for the friction test of coated cutters with a load of $10 \mathrm{~N}$, and both friction tests had a turning radius of $4 \mathrm{~mm}$ and a speed of $400 \mathrm{r} / \mathrm{min}$. The ETC3650h CNC lathe (SMTCL, Shenyang, China) was used for cutting test and an HT250, a gray cast iron with yield strength of $250 \mathrm{MPa}$, was used as the workpiece. The cutting speed was $200 \mathrm{~m} / \mathrm{min}$, the back cutting depth was $0.3 \mathrm{~mm}$, and the feed rate was $0.1 \mathrm{~mm} / \mathrm{r}$.

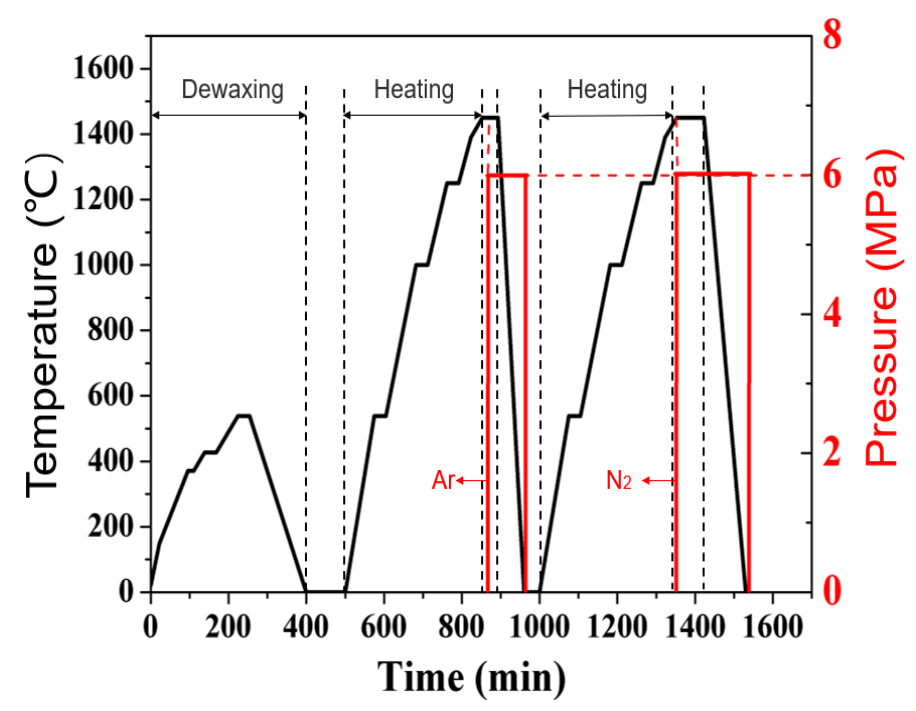

Figure 1. Dewaxing and two-step sinter-hip process for FGCs.

\section{Results and Discussion}

\subsection{Functionally Graded Cemented Carbides}

\subsubsection{Microstructure of FGCs}

Figures 2 and 3 show the microstructure and EDS element distribution of WC-Co-Zr and WC-Ni-Zr FGCs, respectively. The gradient layer thickness of WC-Co-Zr is significantly lower than that of WC-Ni-Zr. Both carbide surfaces contained mainly $\mathrm{Zr}$ and N, and the FCC phase $\mathrm{ZrN}$ was formed during the high-pressure nitriding process [15]. Figure 4 shows the XRD of both FC- 5 and FN-1, which confirms the formation of FCC phase ZrN during high pressure nitriding process.
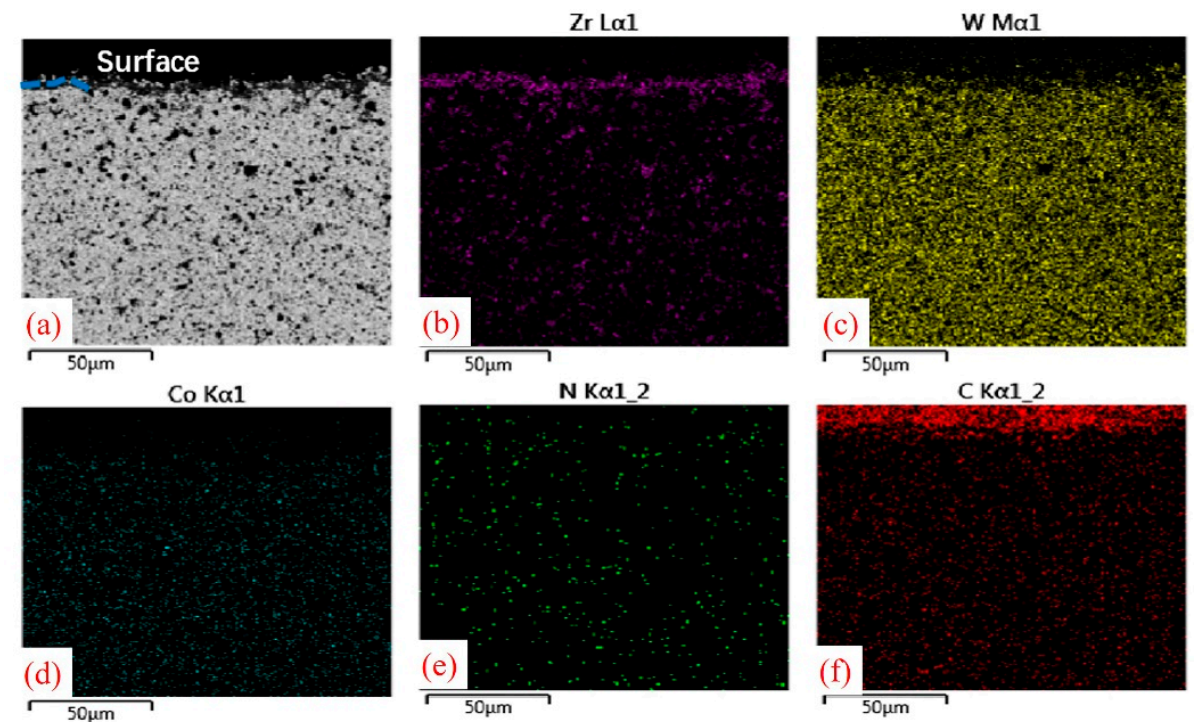

Figure 2. Microstructure and EDS element mapping of FC5-2, (a) microstructure, and (b-f) respective element mappings of $\mathrm{Zr}, \mathrm{W}, \mathrm{Co}, \mathrm{N}$, and $\mathrm{C}$. 

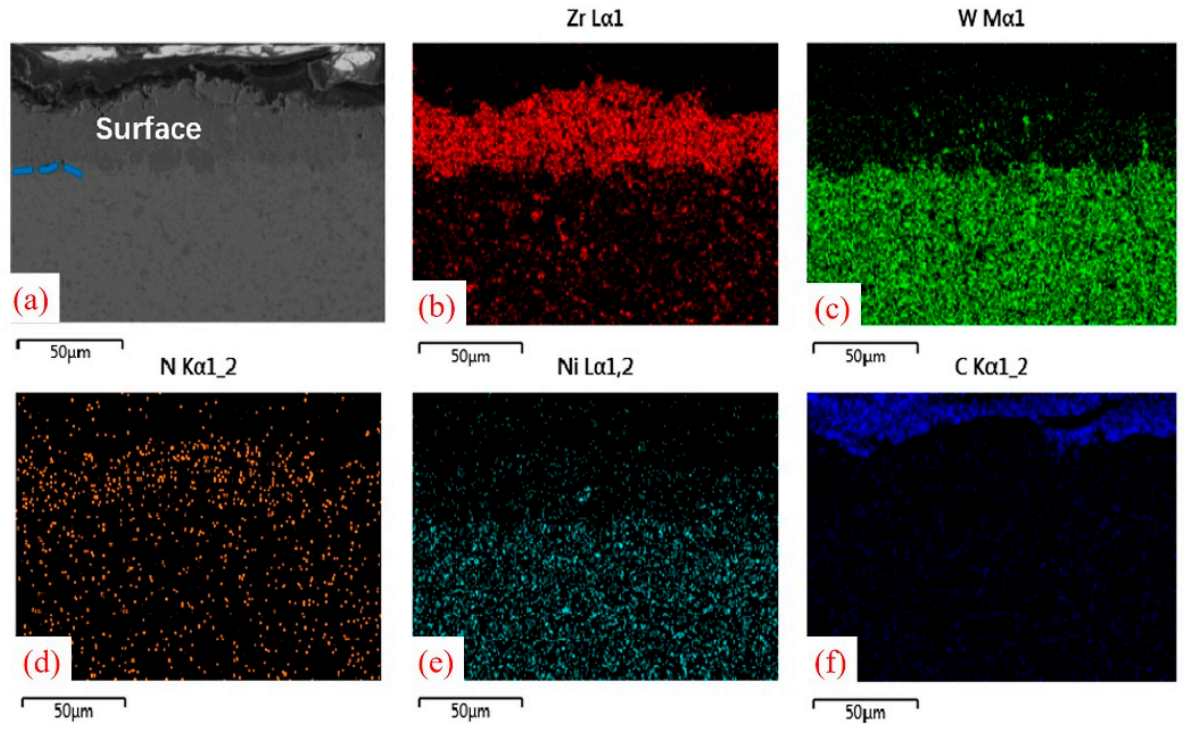

Figure 3. Microstructure and EDS element mapping of FN1-2, (a) microstructure, and (b-f) respective element mappings of $\mathrm{Zr}, \mathrm{W}, \mathrm{N}, \mathrm{Ni}$, and $\mathrm{C}$.

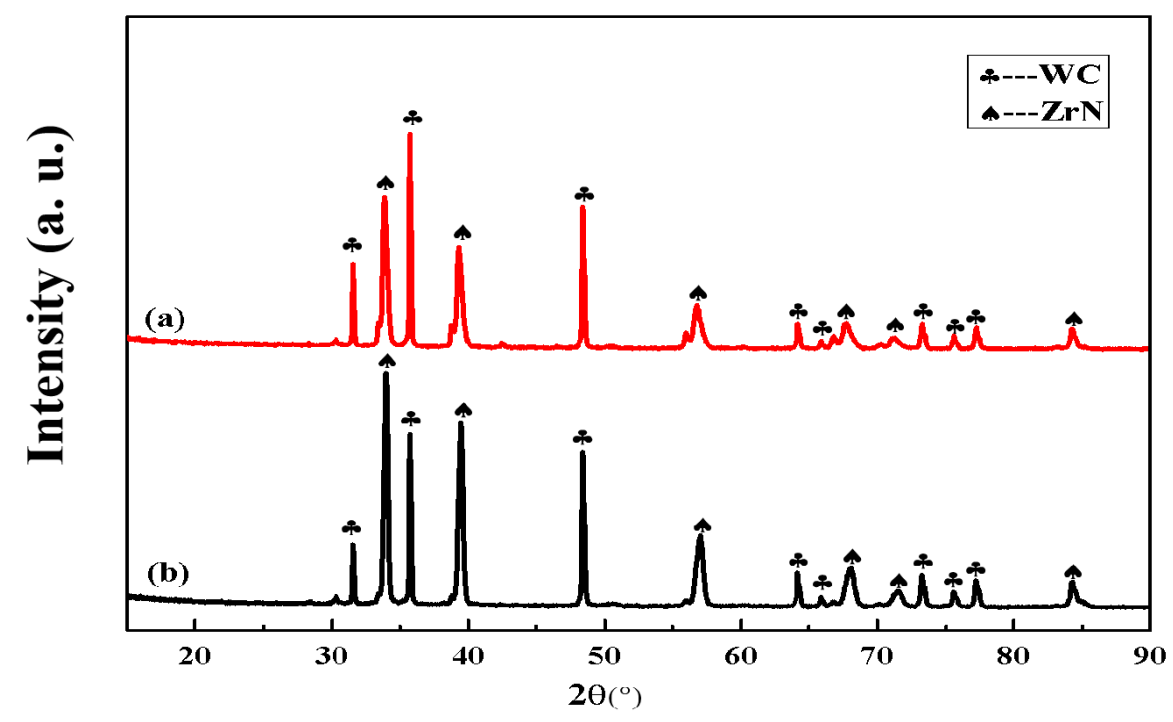

Figure 4. XRD of the surfaces of (a) FC5-2 and (b) FN1-2.

\subsubsection{Friction and Wear Properties of FGCs}

Figure 5 shows the friction coefficient curves of four cemented carbides. The curves can be divided into two stages: the running-in wear stage and the normal friction stage. The curves $C$ and D in Figure 5 represent friction coefficient curves of two FGCs with FCC phase-enriched surfaces (FC5-2, FN1-2). Compared with the carbides with homogeneous microstructure, i.e., A (FC5-1) and B (FN1-1), the friction coefficient curves of the FGCs show abrupt drop in the normal friction stage, which is due to the complete wearing off of the $\mathrm{ZrN}$ surface layer and the exposure of the inner part of FGCs. Figures 2 and 3 show that the thickness of the surface gradient layer of WC-Ni-Zr is significantly thicker than that of WC-Co-Zr, so it takes a longer time before the mutation of friction coefficient for WC-Ni-Zr, as compared with that for WC-Co-Zr. Figure 5 also shows that quite different from the friction behavior of conventional carbides, the formation of $\mathrm{ZrN}$ on the FGC surface can effectively reduce the friction coefficient. 


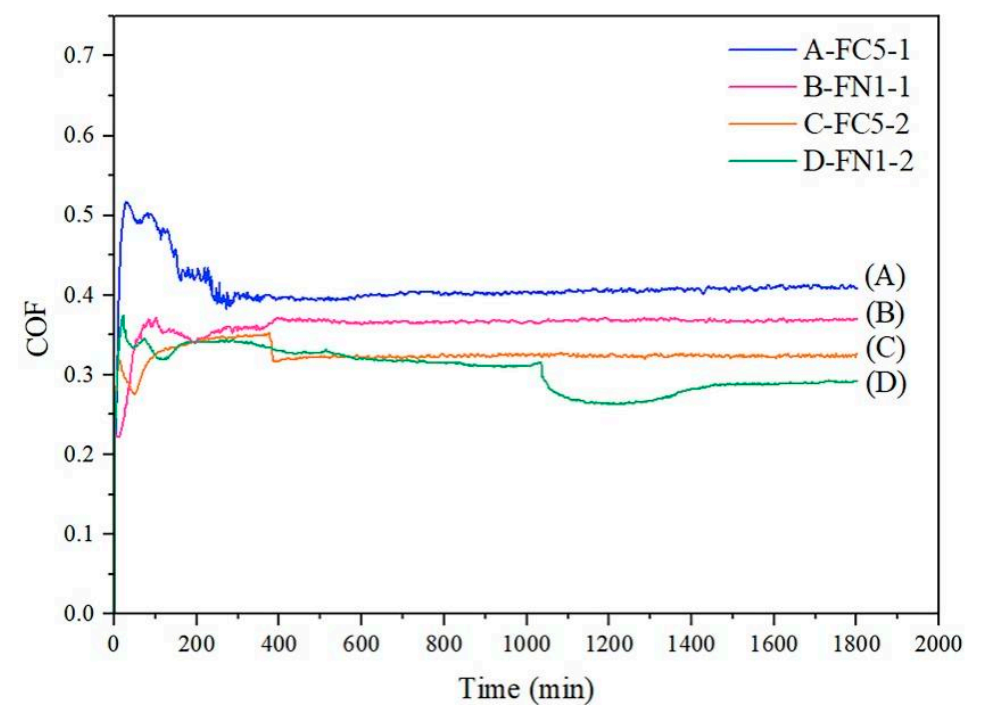

Figure 5. The friction testing curves for both FGCs and conventional carbides.

Figure 6 shows the comparison of wear rates of four cemented carbides. It can be seen that the wear rate of the FGCs is significantly lower than that of conventional carbides with homogeneous microstructure, indicating that a $\mathrm{ZrN}$ layer formed on the surface of the FGCs can significantly improve the wear resistance. Further, the wear rate of the WC-Co-Zr FGCs is slightly lower than that of the WC-Ni-Zr FGCs.

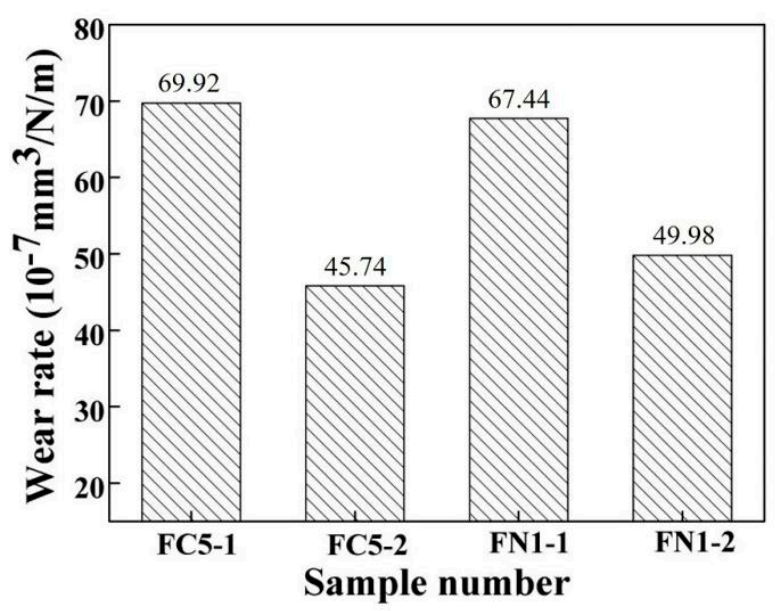

Figure 6. Wear rates of FGCs and conventional carbides.

\subsection{Coated Cutters with FGC and Conventional Carbide Substrates}

\subsubsection{Microstructure of Coated Cutters}

Figure 7 shows the cross-sectional microstructures of four coated carbides. Two types of coated cutters on conventional carbide substrates with homogeneous microstructure have no cracks around the interface between the coating and the substrate, but there are some micro-cracks for the coated cutters on the WC-Ni-Zr FGC substrate (FN1-4). 

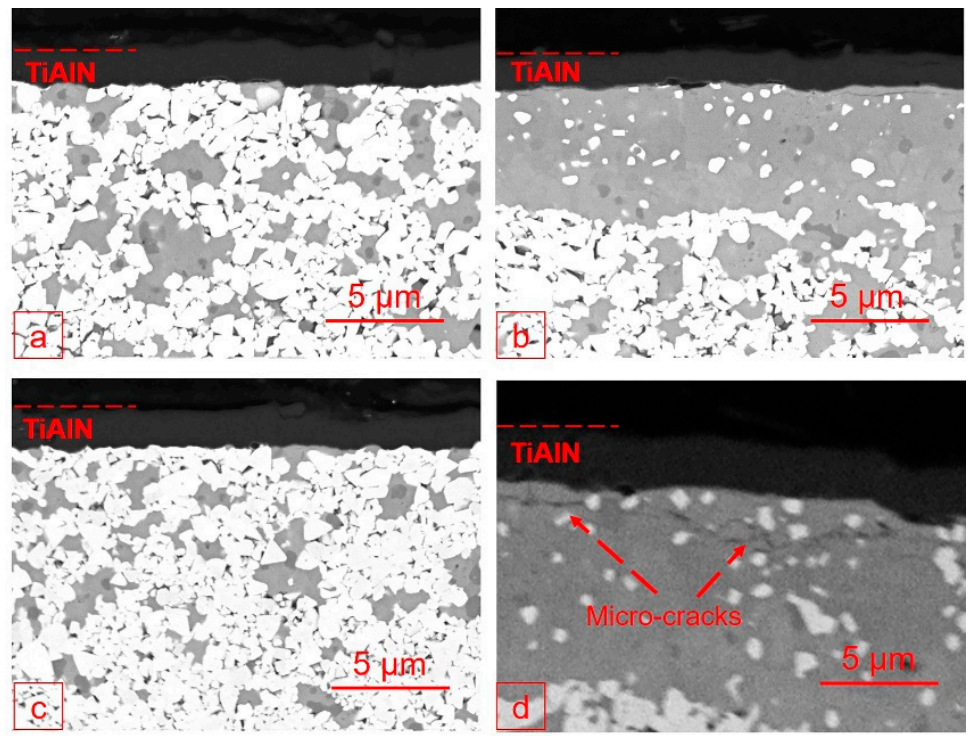

Figure 7. Cross-sectional microstructures of four coated cutters on FGC and conventional carbide substrates, (a) FC5-3, (b) FC5-4, (c) FN1-3, and (d) FN1-4.

\subsubsection{Bonding Strength between Carbide Substrate and Coating}

Figure 8 shows the bonding strength and scratch morphology of the coated cutters. It shows that for WC-Co-Zr, the bonding strength between coating and the FGC substrate is about $15 \%$ higher than that between coating and the conventional carbide substrate. However, for WC-Ni-Zr carbide, bonding strength shows the opposite trend, mainly due to the obvious microcracks between the FGC substrate and the coating. The average hardness of the coatings, measured by nanoindentation, is $32.17 \mathrm{GPa}$.

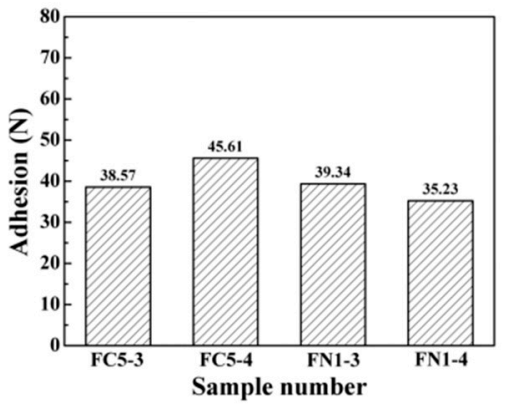

(a)

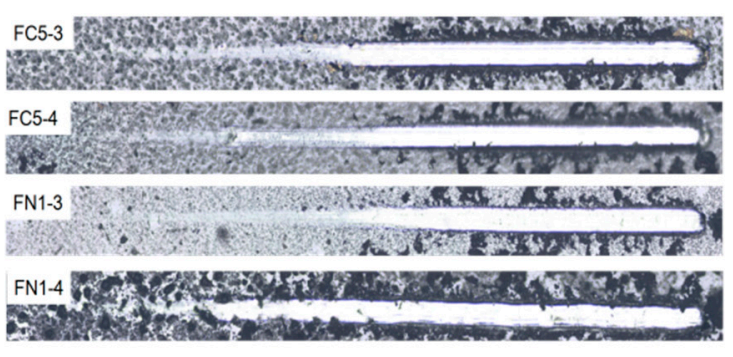

(b)

Figure 8. Bonding between carbide substrates and coatings, (a) bonding strength, and (b) scratching tests.

\subsubsection{Friction and Wear Performance of Coated Carbides}

Figure 9 is the friction coefficient curves of four coated carbides. It can be observed that for both coated WC-Co-Zr with either conventional carbide substrate (curve A) or FGC substrate (curve B), the friction coefficient shows substantial fluctuation, and the friction coefficient of coated WC-Co-Zr with FGC substrate is noticeably lower than that of coated WC-Co-Zr with conventional carbide substrate. For coated WC-Ni-Zr, the friction coefficient corresponding to FGC substrate (curve C) is quite similar to that corresponding to conventional carbide substrate, while the former has wider fluctuation, which is mainly caused by the apparent more micro-cracks of the former, as shown in Figure $7 \mathrm{~d}$. 


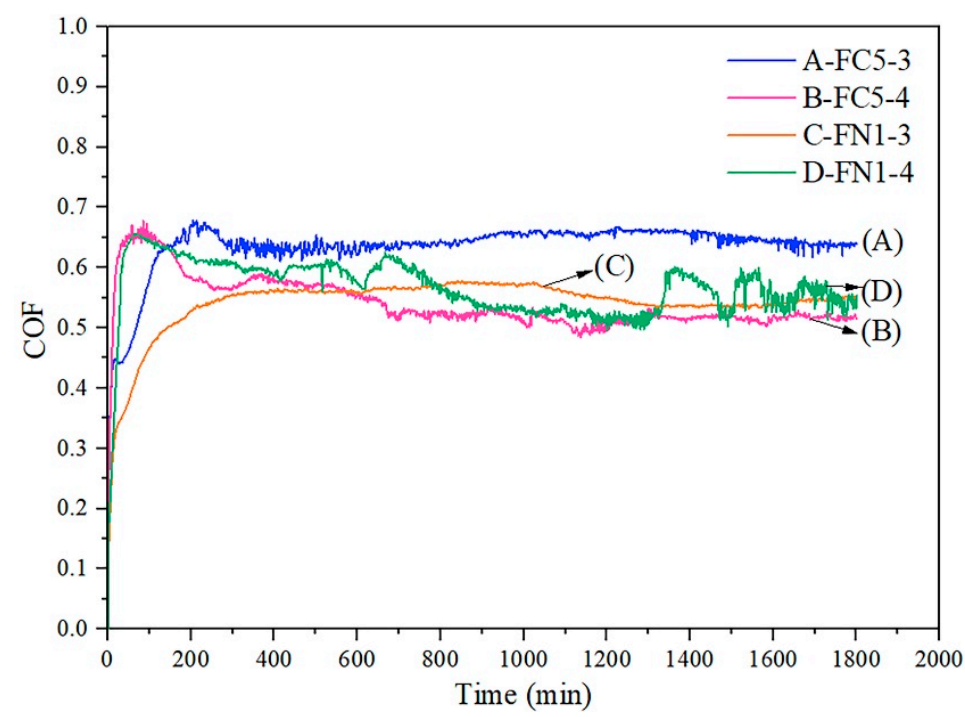

Figure 9. Friction coefficient curves of four coated carbides.

Figure 10 shows the wear rates of four coated carbides. The coated WC-Co-Zr with FGC substrate shows the lowest wear rate, while the coated WC-Ni-Zr with FGC substrate have the highest wear rate due to the existence of micro-cracks.

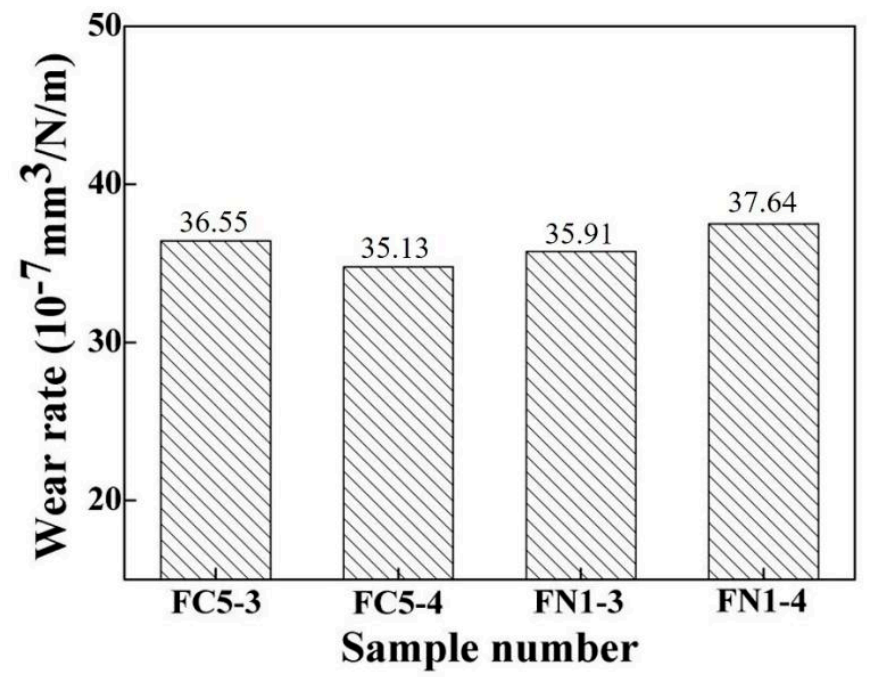

Figure 10. Wear rate of four coated carbides.

\subsection{Cutting Performance of Coated Carbide Cutters \\ 3.3.1. Carbide Cutters}

The wear and cutting behavior of FGCs is quite different from those of conventional carbides $[17,29]$. In this study, both the FGCs and conventional carbides listed in Table 1 were used as the cutters and HT250 was used as the workpiece for cutting experiments. The cutting test parameters are shown in Section 1.

\subsubsection{Cutting Life}

According to ISO-3685, the criterion for cutter failure is average wear of $0.3 \mathrm{~mm}$ on flank face of cutters. Figures 11 and 12 show the dimension of wear vs. time on the flank face of four carbide cutters during cutting test of HT250. It can be seen that the cutting life of WC-Co-Zr is significantly higher than that of WC-Ni-Zr. For WC-Co-Zr, the cutting life of uncoated FGC cutter is about 1.23 times that of conventional carbide cutter with homogeneous microstructure, and the cutting life of the coated cutter with FGC 
substrate is 1.11 times that of the coated cutter with conventional carbide substrate. While for WC-Ni-Zr, the corresponding cutting life improvement of uncoated and coated FGC vs. conventional carbide is 1.54 times and 1.19 times, respectively.

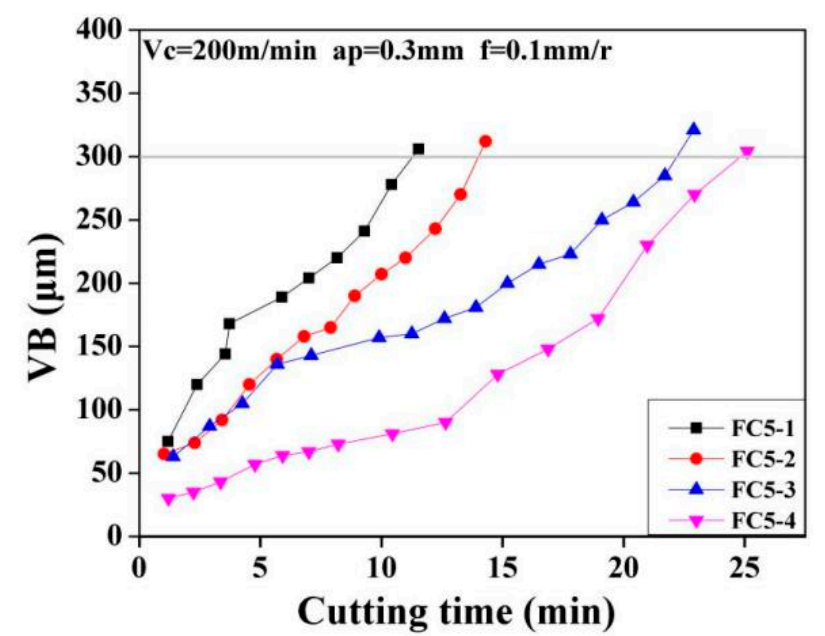

Figure 11. The flank wear VB vs. cutting time for WC-Co-Zr.

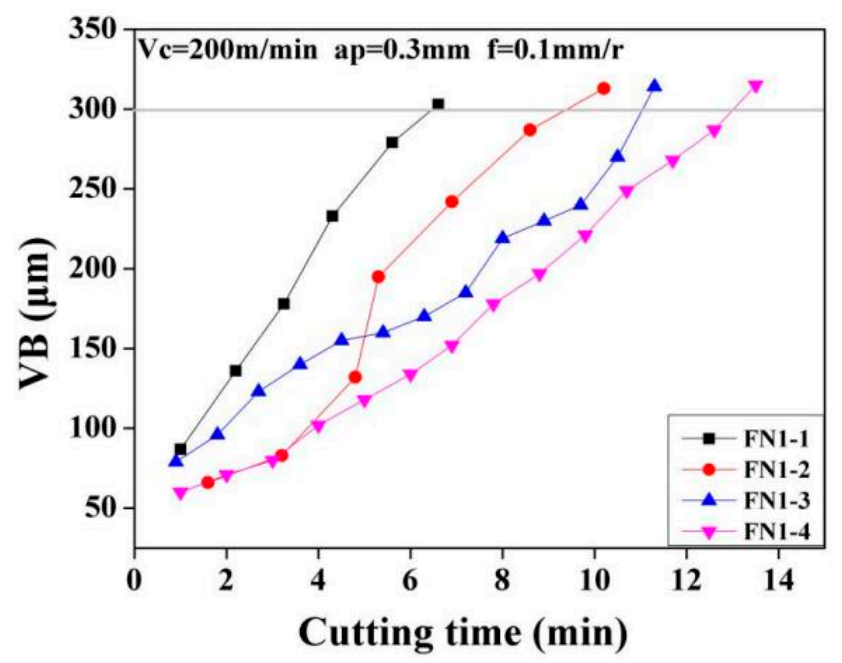

Figure 12. The flank wear VB vs. cutting time for WC-Ni-Zr.

\subsubsection{Wear Mechanism Analysis}

The wear of flank face is commonly used to assess the failure modes of carbide cutters and can be classified as adhesive wear, diffusion wear, abrasive wear, and oxidation wear [30-32].

Figure 13 shows the flank face of WC-Co-Zr cutters after the cutting test. The failure modes are mainly adhesive wear, a certain degree of spalling of coating, and abrasive wear of the cutter tip. Table 2 is the EDS results at Point 1 and Point 2 on the flank face in Figure 13. EDS analysis shows that the gray region (Point 1 ) is the adhesive material (HT250), and the bright region (Point 2) is the exposed carbide substrate after the coating is worn off. The low content of oxygen indicates limited oxidation wear at the high cutting temperature. Furthermore, it can be seen in Figure 13 that there is much less adhesion on flank face of the coated cutters than that on flank face of the uncoated cutters. 

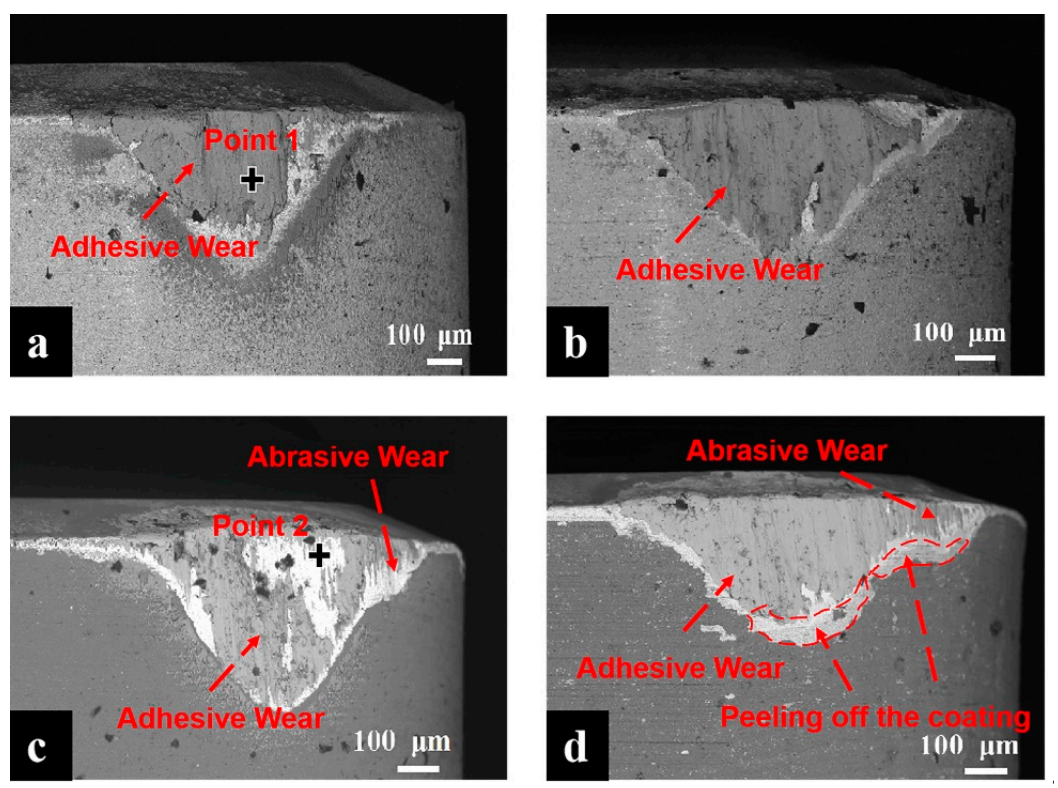

Figure 13. Morphology of flank wear for WC-Co-Zr cutters, (a) FC5-1, (b) FC5-2, (c) FC5-3, and (d) FC5-4.

Table 2. The EDS results of Points 1 and 2 in Figure 12.

\begin{tabular}{ccccccccc}
\hline \multirow{2}{*}{ Area } & \multicolumn{7}{c}{ Element Mass Fraction/\% } \\
\cline { 2 - 9 } & $\mathbf{C}$ & $\mathbf{O}$ & $\mathbf{S i}$ & $\mathbf{Z r}$ & $\mathbf{W}$ & Fe & Mn & Co \\
\hline Point 1 & 7.06 & 1.77 & 2.27 & - & - & 88.91 & - & - \\
Point 2 & 11.5 & 1.98 & - & 11.58 & 71.41 & 2.78 & - & 1.2 \\
\hline
\end{tabular}

Figure 14 shows the morphology of flank face of WC-Ni-Zr after cutting test. The wear modes of WC-Ni-Zr cutters also include mainly adhesive wear, which is the main wear mode of cemented carbide cutters at low and medium cutting speeds [30]. The spalling of coating also occurs and is more severe than that for WC-Co-Zr cutters. Table 3 shows the EDS analysis of the points in Figure 14. Compared with the WC-Co-Zr, the oxidation wear for WC-Ni-Zr is more serious.
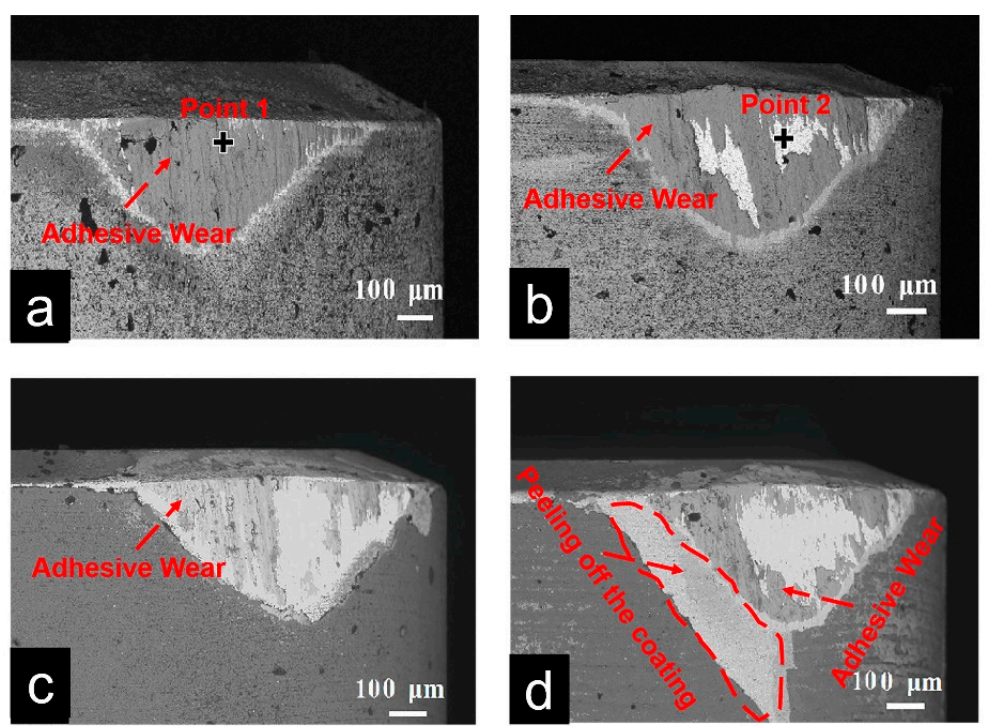

Figure 14. Morphology of flank wear for WC-Ni-Zr cutters, (a) FN1-1, (b) FN1-2, (c) FN1-3, and (d) FN1-4. 
Table 3. The EDS results of Points 1 and 2 in Figure 13.

\begin{tabular}{ccccccccc}
\hline \multirow{2}{*}{ Area } & \multicolumn{7}{c}{ Element Mass Fraction/\% } \\
\cline { 2 - 9 } & $\mathbf{C}$ & $\mathbf{O}$ & Si & Zr & W & Fe & Mn & Co \\
\hline Point 1 & 7.03 & 1.97 & 0.18 & - & - & 89.12 & - & - \\
Point 2 & 9.63 & 2.62 & - & - & 76.72 & 9 & - & 2.02 \\
\hline
\end{tabular}

\section{Conclusions}

In this study, WC-Co/Ni-Zr cemented carbides with homogeneous microstructure (conventional carbides) and the corresponding FGCs with ZrN (face centered cubic phase)enriched surfaces were successfully synthesized using a high-pressure nitriding process. TiAlN coatings were prepared on these carbide substrates by a PVD process, and the mechanical and friction behaviors and cutting test were carried out on these coated and uncoated carbides. It was found that for WC-Co-Zr, friction coefficient and wear rate of coated and uncoated FGCs were, respectively, 20\% and 17\% lower than those of coated and uncoated conventional carbides and for WC-Ni-Zr; uncoated FGC also shows 14\% lower friction coefficient and 26\% lower wear rate than uncoated conventional carbide, while the coated FGC shows wider fluctuation of friction coefficient and $5 \%$ higher wear rate as compared with coated conventional carbide. For WC-Co-Zr, the bonding strength between the coating and the FGC substrate is 18\% higher than that between the coating and the conventional carbide substrate, while for WC-Ni-Zr, the bonding strength between the coating and the FGC substrate, due to micro-cracks, is $10 \%$ lower than that between the coating and the conventional carbide substrate. The cutting tests showed that the cutting life of WC-Co-Zr cutters is about 85\% higher than that of WC-Ni-Zr cutters, and the coated FGCs show $16 \%$ higher cutting life than the coated conventional carbides, followed by the uncoated FGCs, and the uncoated conventional carbides. The cutting test for HT250 shows the main wear mechanism is adhesive wear for all the carbide cutters.

Author Contributions: Conceptualization, X.D. and Z.L. (Zhongliang Lu); methodology, S.L.; investigation, X.X., J.C. and T.L.; formal analysis, Z.Z.; data curation, Z.L. (Zhangxu Li); resources, Z.W.; writing-original draft preparation, S.L.; writing—review and editing, X.D. and Z.L. (Zhongliang Lu); supervision, Z.Q.; project administration, X.D. and Z.Q.; funding acquisition, Z.L. (Zhongliang Lu), X.D., Z.W. and Z.Q. All authors have read and agreed to the published version of the manuscript.

Funding: This research was funded by Science and Technology Project of Guangdong Province, China (Grant No. 2017B090911006), Jihua Laboratory Project (Grant No. X190061UZ190), Foshan Science and Technology Innovation Team project (FS0AA-KJ919-4402-0023), and Heyuan Science and Technology Project (Grant No. HEKE 000781).

Institutional Review Board Statement: Not applicable.

Informed Consent Statement: Not applicable.

Data Availability Statement: Not applicable.

Conflicts of Interest: The authors declare no conflict of interest.

\section{References}

1. García, J.; Ciprés, V.C.; Blomqvist, A.; Kaplan, B. Cemented carbide microstructures: A review. Int. J. Refract. Met. Hard Mater. 2018, 80, 40-68. [CrossRef]

2. Ortner, H.M.; Ettmayer, P.; Kolaska, H. The history of the technological progress of hardmetals. Int. J. Refract. Met. Hard Mater. 2014, 44, 148-159. [CrossRef]

3. Fang, Z.Z.; Koopman, M.C.; Wang, H. Cemented Tungsten Carbide Hardmetal-An Introduction. Compr. Hard Mater. 2014, 1, 123-137.

4. Upadhyaya, G.S. Materials science of cemented carbides-an overview. Mater. Des. 2001, 22, 483-489. [CrossRef]

5. Emani, S.V.; Ramos dos Santos, A.F.C.; Shaw, L.L.; Chen, Z. Investigation of microstructure and mechanical properties at low and high temperatures of WC-6 wt.\% Co. Int. J. Refract. Met. Hard Mater. 2016, 58, 172-181. [CrossRef] 
6. Lu, Z.Y.; Du, J.; Sun, Y.J.; Su, G.S.; Zhang, C.Y.; Kong, X.M. Effect of ultrafine WC contents on the microstructures, mechanical properties and wear resistances of regenerated coarse grained WC-10Co cemented carbides. Int. J. Refract. Met. Hard Mater. 2021, 97, 105516. [CrossRef]

7. Roulon, Z.; Missiaen, J.M.; Lay, S. Shrinkage and microstructure evolution during sintering of cemented carbides with alternative binders. Int. J. Refract. Met. Hard Mater. 2021, 101, 105665. [CrossRef]

8. Shaw, L.L.; Luo, H.; Zhong, Y. WC-18 wt.\% Co with simultaneous improvements in hardness and toughness derived from nanocrystalline powder. Mater. Sci. Eng. A 2012, 537, 39-48. [CrossRef]

9. Yang, G.J.; Gao, P.H.; Li, C.X.; Li, C.J. Simultaneous strengthening and toughening effects in WC-(nanoWC-Co). Scr. Mater. 2012, 66, 777-780. [CrossRef]

10. Salmasi, A.; Andreas, B.; Henrik, L. Geometry effects during sintering of graded cemented carbides: Modelling of microstructural evolution and mechanical properties. Results Mater. 2019, 24, 8-11. [CrossRef]

11. Chen, J.; Zhou, L.; Liang, J.X.; Liu, B.Y.; Liu, J.Y.; Chen, Y.; Deng, X.; Wu, S.H.; Huang, M.J. Effect of initial WC particle size on grain growth behavior and gradient structure formation of bilayer functionally graded cemented carbides. Mater. Chem. Phys. 2021, 271, 124919. [CrossRef]

12. Liu, Y.; Wang, H.B.; Yang, J.G.; He, Y.H.; Long, Z.Y. Relationship between structure and properties of graded cemented carbide. Mater. Sci. Eng. Powder Met. 2005, 6, 356-360.

13. Li, X.F.; Liu, Y.; Liu, B.; Zhou, J.H. Effects of submicron WC addition on structures, kinetics and mechanical properties of functionally graded cemented carbides with coarse grains. Int. J. Refract. Met. Hard Mater. 2016, 56, 132-138. [CrossRef]

14. Zhang, L.; Zhong, Z.Q.; Qiu, L.C.; Shi, H.D.; Layyous, A.; Liu, S.P. Coated cemented carbide tool life extension accompanied by comb cracks: The milling case of 316L stainless steel. Wear 2019, 418, 133-139. [CrossRef]

15. Frykholm, R.; Andrén, H.O. Development of the microstructure during gradient sintering of a cemented carbide. Mater. Chem. Phys. 2001, 67, 203-208. [CrossRef]

16. Tang, S.W.; Liu, D.S.; Li, P.N.; Jiang, L.L.; Liu, W.H.; Chen, Y.Q.; Niu, Q.L. Microstructure and mechanical properties of functionally gradient cemented carbides fabricated by microwave heating nitriding sintering. Int. J. Refract. Met. Hard Mater. 2016, 58, 137-142. [CrossRef]

17. Garcia, J.; Reinhard, P. The role of cemented carbide functionally graded outer-layers on the wear performance of coated cutting tools. Int. J. Refract. Met. Hard Mater. 2013, 36, 52-59. [CrossRef]

18. Ruys, A.J.; Sutton, B.A. 9-Metal-ceramic functionally graded materials (FGMs). In Elsevier Series on Advanced Ceramic Materials, Metal-Reinforced Ceramics, 1st ed.; Ruys, A.J., Ed.; Woodhead Publishing: Cambridge, UK, 2021; pp. 327-359.

19. Carneiro, M.B.; Machado, I.F. Sintering and Model of Thermal Residual Stress for Getting Cutting Tools from Functionally Gradient Materials. Procedia CIRP 2013, 8, 200-205. [CrossRef]

20. $\mathrm{Xu}, \mathrm{X} . \mathrm{L}$. Research on the Production of Gradient Dual-Phase Cemented Carbide by Single Sintering Process. Cem. Carbide 2008, $25,12-18$.

21. Zhang, L.; Chen, S.; Xiong, X.J.; He, Y.H.; Huang, B.Y.; Zhang, C.F. Phase composition, transition and structure stability of functionally graded cemented carbide with dual phase structure. J. Cent. South Univ. Technol. 2007, 14, 149-152. [CrossRef]

22. Zhang, J.F.; Xiong, J.; Li, Y.; Guo, L. The Structure and Performance of Gradient Cemented Carbide for Diamond Coating. Cem. Carbide 2003, 20, 200-203.

23. Wang, H.B.; Lu, H.; Song, X.Y.; Yan, X.F.; Liu, X.M.; Nie, Z.R. Corrosion resistance enhancement of WC cermet coating by carbides alloying. Corros. Sci. 2019, 147, 372-383. [CrossRef]

24. Chen, J.; Deng, X.; Gong, M.F.; Liu, W.; Wu, S.H. Research into preparation and properties of graded cemented carbides with face center cubic-rich surface layer. Appl. Surf. Sci. 2016, 380, 108-113. [CrossRef]

25. Barbatti, C.; Garcia, J.; Sket, F.; Kostka, A.; Pyzallaet, A.R. Influence of nitridation on surface microstructure and properties of graded cemented carbides with Co and Ni binders. Surf. Coat. Technol. 2008, 202, 5962-5975. [CrossRef]

26. Konigshofer, R.; Eder, A.; Lengauer, W.; Dreyer, K.; Kassel, D.; Daub, H.W.; Berg, H. Growth of the graded zone and its impact on cutting performance in high-pressure nitrogen modified functionally gradient hardmetals. J. Alloys Compd. 2004, 366, 228-232. [CrossRef]

27. Akhter, R.; Zhou, Z.F.; Xie, Z.H.; Munroe, P. TiN versus TiSiN coatings in indentation, scratch and wear setting. Appl. Surf. Sci. 2021, 563, 150356. [CrossRef]

28. Gross, K.A.; Lungevics, J.; Zavickis, J.; Pluduma, L. A comparison of quality control methods for scratch detection on polished metal surfaces. Measurement 2018, 117, 397-402. [CrossRef]

29. Mohammadpour, M.; Abachi, P.; Pourazarang, K. Effect of cobalt replacement by nickel on functionally graded cemented carbonitrides. Int. J. Refract. Met. Hard Mater. 2012, 30, 42-47. [CrossRef]

30. Chang, K.S.; Dong, Y.J.; Zheng, G.M.; Zheng, G.M.; Jiang, X.L.; Yang, X.H.; Cheng, X.; Liu, H.B.; Zhao, G.X. Friction and wear properties of TiAlN coated tools with different levels of surface integrity. Ceram. Int. 2021, 10, 105. [CrossRef]

31. Fang, S.Q. Wear Assessment of Cemented Carbide Tools (WC-Co) with Defined Cutting Edges under Grinding-like Service Conditions. Wear 2021, 476, 203744. [CrossRef]

32. Neves, D.; Diniz, A.E.; Lima, M.S.F. Microstructural analyses and wear behavior of the cemented carbide tools after laser surface treatment and PVD coating. Appl. Sur. Sci. 2013, 282, 680-688. [CrossRef] 